by researchers in Germany (F. Schierhorn et al. Glob. Biogeochem. Cycles http://doi.org/qg8; 2013) now suggests that the area of cropland abandoned since 1990 is much larger than most people in the West would have guessed (see page 342 ).

The information that redrew the map was not supplied by sophisticated satellite-borne sensors. Instead, the authors analysed the annual sowing statistics for crops between 1990 and 2009 - which were still hard to come by - and deduced that the area used for grain production in the former Soviet breadbaskets of western Russia, Belarus and Ukraine has decreased by more than one-quarter. This decline is substantially greater than the estimate made, mainly from satellite data, in 2009 by the UN Food and Agricultural Organization.

Why does this decrease matter? Most immediately, millions of hectares of fertile land are lying idle while a growing world population demands more food. As urbanization, desertification and increasing water scarcity constrain the extension of arable land worldwide, this unsown land might look like a precious resource. But as nature gives with one hand, it takes away with the other. These abandoned areas have become important carbon sinks. Substantial amounts of organic carbon have accumulated in their untilled soils and natural vegetation over the past two decades. If intensive agriculture were to resume, this carbon would be rapidly released into the atmosphere as carbon dioxide, contributing to global warming.

The abandoned Eastern European croplands highlight the perennial trade-off between agriculture and climate protection. And they show yet again that the debate over what to do about this needs to be better-informed by more robust data.

Russian soils and forests are a major part of the global terrestrial carbon sink. Russia's last-minute signing of the 1997 Kyoto Protocol on Climate Change (and its possible involvement in a future international agreement) owe much to the prospect of substantial gains from the sale of carbon credits. The possibility that Russia's natural carbon sink has increased is potentially lucrative news for a country whose leaders and scientists often keep a low profile when it comes to global warming.

However, the true size of the Eastern European - and the global terrestrial carbon sink remains disturbingly uncertain. Discrepancies

in various estimates of its size based on changes in land use point to shortcomings in regional and global carbon accounting - a discipline on which any new international climate regime will fundamentally rely. Whether or not the revised estimates on the extent of post-Soviet land abandonment are correct, they underscore the fact that satellite observations of land-use dynamics, in Russia or elsewhere, are no credible guide to a region's carbon balance.

A matter so central to predicting the rate of global warming deserves more attention. But existing remote-sensing technology offers relatively coarse observations of land cover and land-use change, which

"Millions of

fertile land are

lying idle while a growing world population demands more food." Moreover, the spectral fingerprint of an area cation of fertilizer, which affects a soil's carbon-sequestration capacity.

In the absence of reliable satellite observations, land-use dynamics need to be continuously monitored on the ground. A NASA-funded project on land cover and land-use change in western Russia is setting the right tone by incorporating the results of field surveys with remote sensing and statistical modelling. Similar field studies would be desirable in other countries, such as Brazil, Argentina, China and India, where land use is undergoing major transitions.

Ultimately, only improved satellite observations can provide the global data sets required to understand the elusive global carbon sink. The European Space Agency's €400-million (US\$551-million) BIOMASS radar mission, selected in spring as Europe's next Earth Explorer mission and scheduled for launch around the end of the decade, could make a real difference - if mainly in the tropics. Emerging space nations, there is a great opportunity to be seized.

\section{Futures redux}

\section{Can you tell a sci-fi tale in just 200 characters? Then the Nature Futures competition is for you.}

A s 2013 prepares to gasp its last, this issue follows a venerable tradition and looks back at the myriad events, images and people that made the news and shaped the year's scientific agenda (see page 344). These are collected together with a host of highlights on our website (www.nature.com/2013), where there is even an online quiz to test your memory of what happened in science this year (go.nature.com/izlxfn).

There remains one darkened recess of the Nature enterprise that, Scrooge-like, is resolutely refusing to join in. Futures, our sciencefiction column, is doggedly pursuing its agenda and is keeping its sights fixed firmly on the, well, future. For more than a decade, Futures authors have been addressing the key questions that any visionary would wish to answer. Is the human race doomed? What are aliens really like? How will technology change the way we live? And can a soft drink really save your life?

Like the famous Time Lord who turned 50 last month, Futures has enjoyed more than one incarnation - although its present form has proved most stable, appearing as it has on the back page of Nature since July 2007 (nature.com/futures). So far, Futures has published more than 500 stories - and sadly has been forced to reject more than ten times that number (often because of space constraints, although there was one unfortunate time when a pan-dimensional being from a parallel universe took possession of the editor for a week — apologies to those whose e-mails went unanswered).

As well as watching the skies, Futures has surreptitiously infiltrated the office across the hall, where it has activated the sleeper implanted several years ago behind the filing cabinet in the corner. The result is that from January, sci-fi will return to the pages of Nature Physics, offering an extra 12 chances a year to predict what may come to pass. (The submission address is the same: futures@nature.com.)

And the changes don't end there. Back in 2007, we published an anthology of some of the early Futures stories. That too has regenerated, and Futures 1 (note the ' 1 ': there are more planned for 2014) will be available as an eBook from 24 December - ideal, say, for a lastminute virtual stocking filler.

To celebrate this release and the fact that Nature Physics is going back to the Futures, we are offering a chance to win a copy of the eBook, plus a year's subscription to Nature, in a dazzling competition. Inspired by the brevity of Twitter, we want you to tell a short sci-fi story. And we mean short. No more than 200 characters. This truncated tale can be input at these galactic coordinates: go.nature. com/rnrnxx. The closing date is 31 January 2014.

Robots, extrasolar aliens and genetically modified beings are not $\rightarrow$ NATURE,COM To comment online, click on Editorials at: go.nature.com/xhunqv eligible to participate - unless you have managed to take over the planet by the closing date. In which case, can we just say how well your new skin suits you, and please allow us to show you the way to the executive suite. 